\title{
Sex Role Attitudes and Expectations
}

\author{
Michiko Tsuge \\ (北里大学)
}

Sex Role Attitude, Sex Role Expectation, College Students

\begin{abstract}
Purpose
Japanese are known for having traditional sex role attitudes and behaviors. However, recent studies have found that sex role attitudes and behaviors are becoming more liberal among the younger generation. It has also been found that when it comes to sex role attitudes young women are more liberal than young men. This study is part of a larger study on differences between sex role attitudes and beliefs, and anticipated prospective behaviors among college students. This study compared college women's and men's ideal sex roles as well as the sex role behaviors they anticipated enacting in their future marital relationships.
\end{abstract}

\section{Method}

Participants: 146 Japanese single college students between the ages of 18 and 24: 55 were female and 91 were male. Data was collected in April, 2007.

Instruments: 1) The Short-Form of the Scale of Egalitarian Sex Role Attitudes (SESRA-S; Suzuki, 1994) was used to measure the participants' beliefs and attitudes about sex roles. The SESRA-S is a self-report instrument devised to measure "the degree of egalitarianism in sex role" (Suzuki, 1991, p. 129). The SESRA-S consists of 15 items which were designed to measure sex role attitudes. Participants are asked to respond to items on a 5-point Likert scale $(1=$ strongly disagree, $5=$ strongly agree $)$. The higher the score, the more liberal the sex role attitude. Participants were specifically instructed to answer regarding their ideal role in their future marital relationship.2) The Modified SESRA-S was used to measure expected sex role behaviors in their future marital relationship. It was created by the author based on the SESRA-S (i.e., for each item on the SESRA-S measuring a sex role attitude there is a corresponding item on the Modified SESRA-S measuring a behavior resulting from that attitude). Higher scores indicate more liberal sex role behaviors.

Statistics: The study utilized ANOVA as well as paired t-tests to investigate the relationship between women's and men's sex role attitudes and anticipated sex role behaviors in their future marital relationships. Paired-T tests with the Bonferroni correction were performed on all 15 items of SESRA-S as well as on the overall SESRA-S score in order to see if there were significant differences between attitudes and beliefs about sex roles and anticipated sex role behavior.

\section{Results}

Results indicated that overall female college students' sex role attitudes in regard to their future marital relationship were more liberal than what they believe their actual sex role behaviors will be. Overall in terms of ideal role in future marital relationships, female college students' were more liberal than men. Overall results also indicated that female college students are more liberal in overall anticipated prospective behavior in their future marital relationship than male college students. $(\mathrm{t}[144]=3.15, \mathrm{p}<.005)$. In their prospective behavior in marital relationship, the female college students presented more liberal attitudes than male students on modified SESRA-S item 2, 4, and 10. Although there was no significant difference between overall male college students' ideal role in future marital relationship and what they think their actual role would be $(\mathrm{t}[180]=.593$, NS), there are some contradiction presented some items on their ideal and prospective sex role behavior in marital relationships. For male college students their sex role attitudes were more liberal than their prospective marital behaviors in SESRA-S Items 1, 2, 12, 14, and 15. On the other hand their prospective behavior in their marital relationship were more liberal than their sex role attitudes as indicated by modified SESRA items, 3, 4, 6, 11, and 13 .

\section{Discussion}

In this study, college women presented more liberal sex role attitude than college men. However in comparison to college men, college women were less hopeful in terms of having their ideal role translated into their prospective marital relationship. This could be an indication of the difference in the meaning of marriage for female and male college students. Future study is needed to find what contributes to college women with liberal attitudes being less optimistic that these attitudes will translate into behaviors in their future marital relationships. Past studies have shown that item 8 , bringing up children has been reported as being the most important job for a woman, which seemed to be a key item for both Japanese wives (another study) and college women. This could be an indication that being a mother and the main care giver is strongly believed to be the role for a woman across generations. However this was not supported by college men. They do not see their ideal wives most important job being to raise children (Mean=2.8, $\mathrm{SD}=1.1$ ) nor do they expect that to be the case in their future marriage. (Mean=2.8, $\mathrm{SD}=1.1$ ). However, interestingly enough, college men do not stated their strong with for their wives to keep working when they have children (Mean=3.21, $\mathrm{SD}=.85$ ), although they do see that is what is likely to happen (Mean=4.65, $\mathrm{SD}=.69$ ). This could indicate that while college men do not have strong opinion their wives to be a care giver to their child, they also assume that their wives may wish to keep their careers and not have motherhood be their only role in life. Further research is needed to see what factors contribute to the interaction between male college students' ideal sex role and their prospective relationship in future marriages.

\section{References}

Suzuki, A. (1994). Construction of a short-form of the scale of egalitarian sex role attitudes (SESRA-S). The Japanese Journal of Psychology, 65, 34-41.

Suzuki, A. (1991). Predictors of women's sex role attitudes across two cultures: Unites States and Japan. Japanese Psychological Research, 33, 126-133. 